\title{
https://helda.helsinki.fi
}

\section{Virtual reality as a recovering environment - Implications for design principles}

\section{Lähtevänoja, Antti}

Springer International Publishing AG

2020-02-01

Lähtevänoja , A , Holopainen , J , Mattila , O , Södervik , I , Parvinen , P \& Pöyry , E 2020 ,

Virtual reality as a recovering environment - Implications for design principles . in D A

Alexandrov, A V Boukhanovsky, A V Chugunov, Y Kabanov, O Koltsova \& I Musabirov

(eds) , Communications in Computer and Information Science : Fourth International

pÿConference, DTGS 2019, St. Petersburg, Russia, 1921 June, 2019: Revised Selected

Papers . Communications in Computer and Information Science, no. 1038 , Springer

International Publishing AG, Cham, Digital Transformation \& Global Society, St.

Petersburg , Russian Federation , 19/06/2019 . https://doi.org/10.1007/978-3-030-37858-5_43

http://hdl.handle.net/10138/323977

https://doi.org/10.1007/978-3-030-37858-5_43

unspecified

acceptedVersion

Downloaded from Helda, University of Helsinki institutional repository.

This is an electronic reprint of the original article.

This reprint may differ from the original in pagination and typographic detail.

Please cite the original version. 


\title{
Virtual reality as a recovering environment - Implications for design principles
}

\author{
Antti Lähtevänoja ${ }^{1}$, Jani Holopainen ${ }^{2}$, Osmo Mattila ${ }^{3}$, Ilona Södervik ${ }^{4}$, \\ Petri Parvinen ${ }^{4}$, Essi Pöyry ${ }^{4}$ \\ ${ }^{1}$ University of Jyväskylä, Seminaarinkatu 15, 40014, Jyväskylä, Finland, \\ antti.j.lahtevanoja@student.jyu.fi \\ ${ }^{2}$ University of Helsinki, Yliopistonkatu 4, 00100, Helsinki, Finland, \\ jani.m.holopainen@helsinki.fi \\ ${ }^{3}$ University of Helsinki, Yliopistonkatu 4, 00100, Helsinki, Finland, \\ osmo.mattila@helsinki.fi \\ ${ }^{4}$ University of Helsinki, Yliopistonkatu 4, 00100, Helsinki, Finland,
}

\begin{abstract}
In this study, a simulated, VR-based environment was built and analyzed to explore if a VR environment can possess recovering effects. 61 university students tested a VR application depicting a forest and answered survey questions about the experience. The results showed that VR-environment can indeed have recovering effects. Moreover, when comparing to previous studies in real forests, the recovery effects were at similar levels. The study results suggest that as the VR-based environments can possess recovery effects, they can work as recovery environments at schools or similar environments. The study results offer implications for the designers and propose design principles to build recovering VR environments. Future research avenues to scrutinize the results in various research contexts are discussed.
\end{abstract}

Keywords: Virtual reality, Restorative environment, Directed attention fatigue, Design principles.

\section{Introduction}

Nowadays, we live in a fast-paced world: we have to constantly process information and stimuli from various sources and decide what is crucial and what can be ignored. That is, cognitive activity is needed.

Prolonged cognitive activity can lead to mental fatigue and directed attention fatigue [15], which hinder focusing and learning [4]. Concentration and focusing problems can be seen especially in schools, as cognitive activity is at the core of learning. Learning involves multiple cognitive processes, such as absorbing, processing, remembering and retrieving information, all of which require attention [12, 22].

Recent research has showed that natural environments can decrease attention fatigue $[3,17]$. Still, in urban settings, this can be a problem. Natural environments are sometimes out of reach, or people don't have the time to visit those environments, 
especially during a school day. Therefore, visiting VR-based recovering environment could work as a substitute for visiting natural environments and offer similar recovering experiences.

The aim of this study is to validate whether a VR environment can possess recovery effects and thus work as a recovering environment in different contexts, like schools. Simulated, VR-based environments would make it possible to have an easy access to a restorative environment during a school day, for example. Restorative environments could help students recover from directed attention fatigue during a recess.

In addition, as previous research has indicated that VR may cause excessive cognitive load on students (e.g. [20]), we need more information if any VR environment can have recovering effects. This research aims at giving practical implications for the designers about the components and design principles to build recovering VR environments. The implications can be used to build recovering VR environments for schools or to build VR learning and education applications with less cognitive load.

\section{Literature: attention, fatigue and restoration}

Attention is essentially defined as the ability to focus on only desired or necessary stimuli, as well as the ability to exclude unnecessary or unwanted stimuli [12]. With attention, it is possible to absorb new information through various senses and select what we pay attention and what we ignore. Furthermore, being able to direct our attention makes it possible to pay attention to the task at hand. In the case of unautomated tasks, paying attention to the task is crucial for them to be remembered, as our working memory has limits [12]. To learn, one has to hold information in the working memory and then move it to the long-term memory. To do this, we need to use attention [37]. As Miller [23] summarizes; without attention, there is no memory. Furthermore, without memory, there is no learning.

Directed attention is a mechanism which allows one to control the focus of thought and perception [16]. It allows one to block and inhibit distractions and competing stimuli during purposeful activity [13]. According to Kaplan and Berman [14], directed attention is not tied to particular stimulus patterns, unlike involuntary attention. Prolonged directed attention causes mental effort and is mentally exhaustive, and this exhausted state is called as directed attention fatigue [15]. Directed attention fatigue constitutes a substantial impairment in one's mental competence, and therefore it is important to restore from directed attention fatigue [16].

Kaplan [15] suggests that sleep itself is insufficient for recovering from directed attention fatigue (DAF). To be able to recover from DAF, one needs to find another basis for maintaining one's focus; an alternative mode of attending. This mode should render the use of directed attention temporary unnecessary [15]. One way to achieve this is to use restorative experiences. According to the attention restoration theory, ART [15], a restorative experience should have four components: fascination, being away, extent and compatibility. Fascination suggests that something in the environ- 
ments fascinates people. This can be for example objects, walking in natural settings or the environment as a whole. Being away in another setting frees one's mind from the mental activity caused by the directed attention. Extent refers to the environment: it should be rich and coherent enough to constitute as a real world. Finally, compatibility suggests that the environment should fit to what one would like to try to do and would like to do [15].

Natural environments, such as parks and forests work well as restorative environments, as they involve characteristics required for restorative experience, and requires only involuntary, effortless attention [13]. Previous research has proven that restorative natural environments have indeed helped recover from directed attention fatigue, and that natural environments have generally had more restorative effects than built environments $[2,3,8,11,17,31]$.

Furthermore, simulated recovering environments have also been found out to have recovering effects, though not so strong as the natural environments [3, 32]. However, simulated, virtual reality -based environments with head-mounted -displays (HMD) have not been tested widely. HMD allows user to immerse completely to the simulated world, hence offering a comprehensive experience. As suggested by Nordh [24], because of the immersion, virtual reality techniques may provide more reliable results of restorativeness than photos, for example.

Based on the suggested components of restorative environment [15] and subsequent studies on recovering environments, the present study aims to build a recovering VR-based environment. The recovery effects are validated in an experiment with a survey applying contemporary scales and comparing the results with the previous recovery studies on various environments. Based on the results we propose design principles to guide designers for building recovering VR-environments.

\section{Data and methods}

In this study, a simulated, VR-based forest-environment was built following the components introduced by Kaplan [15]: compatibility, being away, extent and fascination. As suggested by the previous research on recovering environments, we modeled a typical boreal forest (Fig. 1) into a VR environment. According to many studies forests are also environments that people like to visit and be oftentimes [31] complying with the compatibility as a design component. The research setup was built in the middle of a city in one of the busiest lobby areas in the city center. In addition, the data collection was done during the busiest office and teaching hours. All this was to create compatibility with another suggested design component - being away. In terms of the extent -component the modelled forest environment represented every little detail from a typical Finnish forest, in order to be rich enough to constitute as a real world [15]. In addition, as Nordh et al. [24] suggests, bushes and trees were created to create psychological distance and to support the being away -component, as well as the extent -component. The coherence with typical trees and undergrowth was validated by expert biologists. Finally, the fascination-component was built by including beautiful and pleasant elements such as flying butterflies [21], birds singing [25], 
sounds of gentle wind, ability to see horizon and landscape, ability to see a tree with bark and leaves very close as well as ability to see undergrowth very close [24]. In addition, a blue sky and shining sun was built to make the overall layout and the color temperature very warm, and to increase the restoration effect [28]. All the sounds were played through headphones, while the length of the sound loop was adjusted long enough that in the test use no loop was recognized. VR-environment was viewed through HTC Vive, a head-mounted display (HMD).

In order to validate the possible recovery effects of the modelled VR forest environment, we followed the previous studies on perceived recovery in natural environments, the restorative outcomes, subjective vitality and emotions. These outcomes were measured in a survey before and after the treatment. VR-based environments have not been studied widely yet and therefore, the measures which has been used to evaluate the recovery and restorativeness in natural settings were applied also in this study. Restoration outcomes were measured using Restoration Outcome Scale (ROS) [18]. ROS scale consisted of six items, which measured reflected relaxation, attention restoration and clearing one's thoughts [18]. Restoration Outcome Scale (ROS) has been used to measure restoration experiences in physical surroundings such as favorite places [18]. It is based on the scales by Hartig et al. [10] and Staats et al. [27] and finalized by Korpela et al. [18]. Subjective vitality was measured using Subjective Vitality Scale (SVS) [26]. In this study, an updated and validated version of SVS scale was used [5]. The scale consisted of seven questions, which measured participant's subjective vitality (e.g. "I feel alive and vital"). Positive and negative feelings were measured with Positive and Negative affect scales Affect Schedule (PANAS) [34]. PANAS scale consisted of ten positive and ten negative affect questions (e.g. interested, excited, distressed, ashamed) [34] and has been validated by Crawford and Henry [6]. Across all questionnaires, questions were answered using a Likert scale from 1 to 7. 


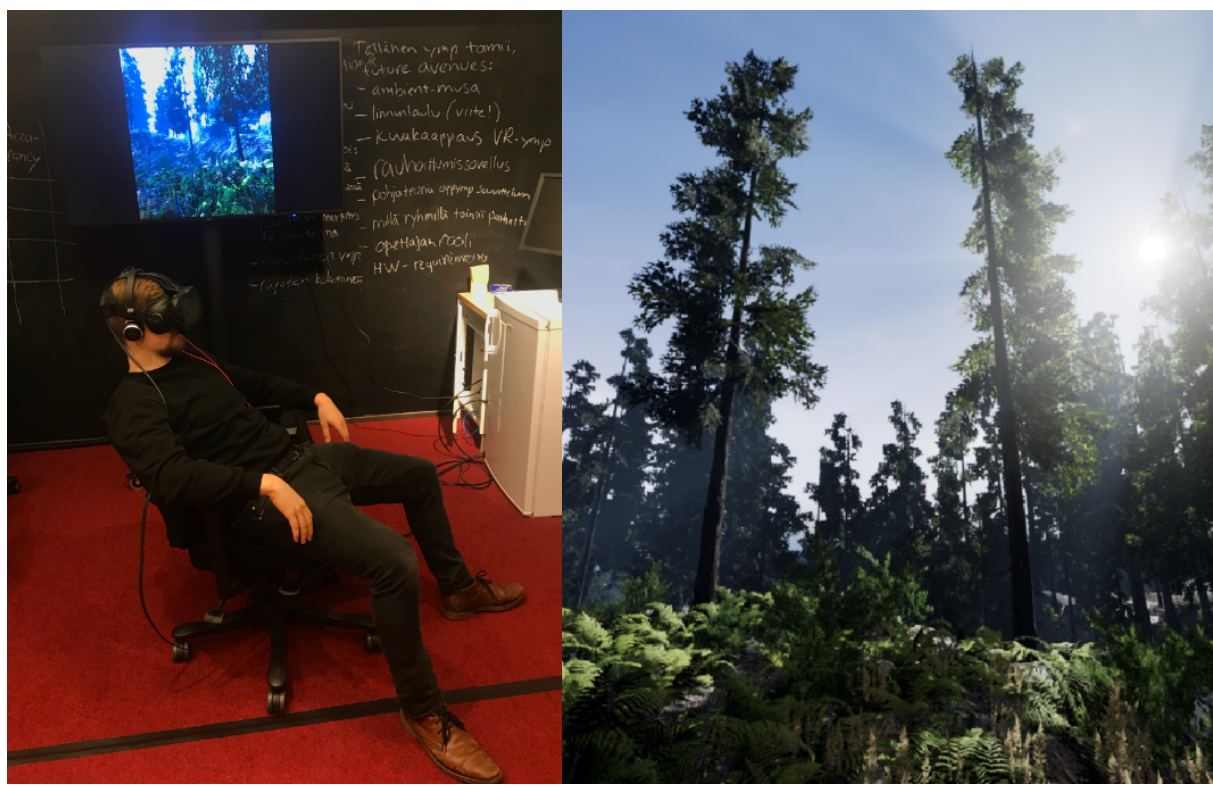

Fig. 1. Participant experiencing the VR-environment and screenshot from the environment.

61 respondents participated the study. $43 \%$ of the participants were female, $54 \%$ male and 3\% were else. $59 \%$ of them had used VR before. Students were asked to visit the test randomly as they passed by. All tests were made between during 8 am and 4 pm, during the normal school days. All participants were Finnish speaking and the questionnaires were in Finnish.

Participants were tested individually. They started by answering the first set of ROS, SVS and PANAS questionnaires. After that, they were asked to sit down on an office chair and a researcher helped them to put on the VR-headset so they can see clearly. Participants were guided to sit down and just be in the virtual reality, and that they could spin the chair freely. A researcher told that he will tap the participant's shoulder when the experience is over. After guidance, the researcher put on the headphones for the participants. The participants stayed in the VR-environment for five minutes. After that, the researcher tapped their shoulder and helped participants to remove the headset. Participants were then asked to fill the second set of the same questionnaire. After completing the questionnaire participants were guided to leave the research space.

The reliability of each factor (SVS, PANAS, ROS) was tested by using Cronbach's alphas. For every measure, a sum variable was formulated, and a mean was calculated from sums. A paired-sample T-test was used to determine whether the mean difference of each sum variable between pre- and post -treatment was statistically significant. The one-way non-parametric ANOVA (Mann-Whitney) was used to test whether there was any of the background variables (age in 2 categories, gender, previous 
experience of using VR) explain the change in any of the sum variables. Analyses were completed utilizing the SPSS Statistics 25 -software.

\section{$4 \quad$ Results}

The scale statistics for ROS, SVS, PANAS POS and PANAS NEG are presented in the Table 1. All psychological measures had good Cronbach's $\alpha$, ranging from .86 to .91. and were in line with previous studies (e.g. [31]). The mean scores and standard deviations are presented in the Table 1 . When comparing the means of the sum variables (two-way), all of the results show a positive change in all the recovery results with a confidence level of $95 \%$ as follows. The mean of restoration outcomes (ROS) increased from $4.13(\mathrm{SD}=1.14)$ to $5.31(\mathrm{SD}=0.93)$ by $1.15(\mathrm{SD}=.99, \mathrm{t}(59)=9.01$, $\mathrm{Cl}=.89,1.4, \mathrm{p}<.001)$. The mean of positive feelings increased from $4.72(\mathrm{SD}=1.01)$ to $5.01(\mathrm{SD}=0.93)$ by $.36(\mathrm{SD}=.75, \mathrm{t}(57)=3.70, \mathrm{Cl}=.16, .55, \mathrm{p}<.001)$. The mean of negative feelings decreased from $2.24(\mathrm{SD}=.84)$ to $1.60(\mathrm{SD}=.69)$. by $-.65(\mathrm{SD}=.59$, $\mathrm{t}(59)=-8.50, \mathrm{Cl}=-.80,-.49 \mathrm{p}<.001$ ). Reported vitality (SVS) increased from 4.62 $(\mathrm{SD}=1.14)$ to $5.30(\mathrm{SD}=.87)$ by $.65(\mathrm{SD}=.78, \mathrm{t}(57)=6.34 \mathrm{Cl}=.44, .85, \mathrm{p}<.001)$. For background variables, the one-way non-parametric ANOVA (Mann-Whitney) showed a statistically significant difference $(\mathrm{p}=0.026)$ only in the increase of positive feelings (the change of PANAS POS). The mean of the positive feelings increased more for the users without any previous VR-experiences $(\mathrm{n}=23)$ : from $4.52(\mathrm{SD}=1.01)$ to 5.22 $(\mathrm{SD}=0.80)$ compared to the ones with previous VR-experience $(\mathrm{n}=35)$ : from 4.85 $(\mathrm{SD}=1.00)$ to $5.00(\mathrm{SD}=1.01)$.

Table 1. Scale statistics of all psychological measures

\begin{tabular}{lllllll}
\hline & \multicolumn{2}{c}{$\begin{array}{c}\text { Before } \\
\text { viewing }\end{array}$} & & \multicolumn{4}{c}{$\begin{array}{c}\text { After } \\
\text { viewing }\end{array}$} \\
\hline \multirow{2}{*}{ Mean } & SD & Cron $\alpha$ & Mean & SD & Cron $\alpha$ \\
ROS & 4.13 & 1.14 & .88 & 5.31 & 0.93 & .86 \\
SVS & 4.62 & 1.14 & .91 & 5.30 & 0.87 & .87 \\
PANAS POS & 4.72 & 1.01 & .90 & 5.01 & 0.93 & .90 \\
PANAS NEG & 2.24 & 0.84 & .86 & 1.60 & 0.69 & .86 \\
\hline
\end{tabular}




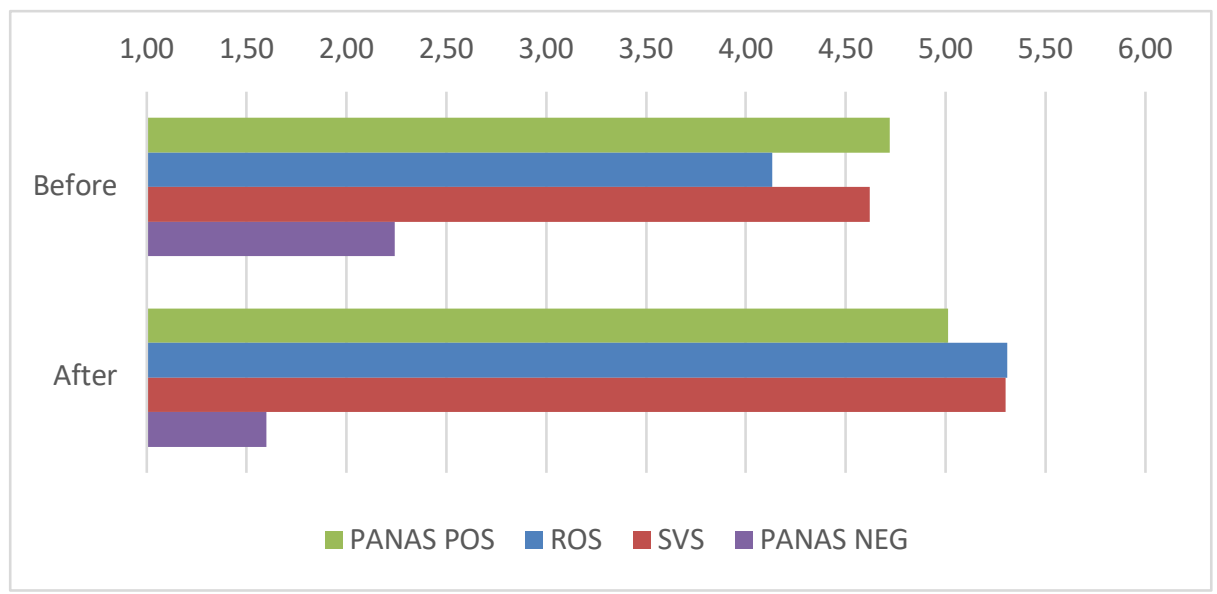

Fig. 2. Mean scores before and after the VR- based recovering experience.

\section{Discussion}

Results showed statistically significant changes with all psychological measures. Participant's perceived restoration outcomes, subjective vitality and positive thoughts increased, while negative thoughts decreased. These results indicate that simulated, VR-based environment can indeed have recovering effects. When comparing to previous restorative environment studies, result of VR-based simulation were as good or exceeded the results achieved from the real natural environments, such as urban woodlands [31].

Taylor and Kuo [30] proposes for schools to use nature environments in school breaks to recover students from the directed attention fatigue. Our results suggest that VR-based environments can work likewise. For example, VR-based restorative environment could be used during school day or workday to recover people from directed attention fatigue. Furthermore, our results suggest that high cognitive load, which is typically a challenge for learning environments utilizing VR (e.g. [20]), could possibly be decreased using recovery components.

Kaplan [15] suggested four-factor solution on his Attention Restoration Theory (ART): fascination, being away, extent and compatibility. These components were used to design and model a recovering VR-based environment. The table 2 summarizes these components and derived design principles modelled and tested in this study. These are also the proposed design principles for the designers to build recovering VR-based environments. As summarized in the Table 2, there are also several existing studies from various disciplines having aligned results with the proposed design principles. However, the proposed principles also raise several questions and need for validation by the future research. For example, among the proposed features there might be insignificant or even negative ones (causing cognitive load). Therefore, experimentation of different fascination features to discover the single feature impact 
and significance is suggested. In addition, experimentation on new possible features extracted from the multidisciplinary literature should be carried out. Furthermore, it is important to study environment features in many various contexts and groups. For example, some groups or contexts may emphasize one component over the another, and therefore they would benefit from a different environment.

Flying butterflies and singing birds have been found out to have a restorative effect in previous studies [21, 25]. Ratcliffe et al. [25] further suggest that bird singing distracts one from cognitive or affective demands, therefore connecting to the fascination -component of Kaplan's [15] ART theory. That is the case also with flying butterflies and sounds of gentle wind [1], as they direct one's attention to them. The ability to see horizon, landscape and close nature objects has also been found out to have a restorative effect $[15,24,29]$, mainly through the fascination -component. In addition, the effect of seeing blue sky and the sun [28] may also be categorized to the fascination -component. As Kaplan [15] suggests, many fascinations in the nature hold the attention, but not in a dramatic fashion, and therefore has a restorative effect. With fascination component, future research could focus on determining how a single feature (e.g. flying butterflies) affects to the whole restorativeness of the environment.

In terms of the design component "being away", the effect of different contrasted environments on different user segments should be evaluated. For instance, for some segments or in some other venues the "being away" effect might be achieved by visualizing some other far-distance places than forests. Tyrväinen et al. [31] conducted a research where three different environments (built-up city centre, a city park and urban woodland) were studied. Results indicated that the perceived restorativeness was higher in the woodlands than in the urban park. It would be beneficial to study, whether this kind of differences could be found also in the context of VR environments. While there are some previous cues about the reflection of extent, realness and greenness to create psychological distance and achieve recovery $[15,24]$ there are also some studies showing that the fantasy can also create flow and embodiment which can be the factors for a recovering experience [7]. This gives a suggestion for the future research to explore to what extend the environment needs to reflect a real and what is the recovery effect of a fantasy in a VR-environment. Finally, as the previous research has suggested the nature environments, such as forests, to be compatible for the recovery, the possibility of some other environments having similar or better effects should be researched.

Compatibility suggests that the environment should fit what one is trying to do in the environment [15]. According to Kaplan [15], compatibility has two ways: one's purposes fit what the environment demands, and the environment gives enough information needed to meet one's purposes. Essentially, in the context of restorative VR environment this can mean that a) the user wants to relax and recover and b) the environment provides enough information and right setting for the user to do this. More research needs to be conducted to know what are one's purposes when viewing a restorative environment: do users want only to explore freely, or is there more purposes, for example a need to do relaxing activities? This information would be vital when designing restorative VR environments. 
Table 2. Proposed design principles for recovering VR-environments

\begin{tabular}{|c|c|c|}
\hline Design component & $\begin{array}{l}\text { Confirmed by previous } \\
\text { research }\end{array}$ & Future research \\
\hline \multicolumn{3}{|l|}{ Fascination } \\
\hline Flying butterflies & Marselle et al. [21] & $\begin{array}{l}\text { Experimentation of differ- } \\
\text { ent fascination features to } \\
\text { discover the single feature } \\
\text { impact and significance. }\end{array}$ \\
\hline Singing birds & Ratcliffe et al. [25] & $\begin{array}{l}\text { In addition, experimenta- } \\
\text { tion on new possible fea- } \\
\text { tures extracted from the } \\
\text { literature. }\end{array}$ \\
\hline Sounds of gentle wind & Abbot et al. [1] & \\
\hline $\begin{array}{l}\text { Ability to see horizon / } \\
\text { landscape }\end{array}$ & Stigsdotter et al. [29] & \\
\hline $\begin{array}{l}\text { Ability to see close na- } \\
\text { ture objects }\end{array}$ & $\begin{array}{l}\text { Kaplan [15]; Nordh et al. } \\
\text { [24] }\end{array}$ & \\
\hline Blue sky & White et al. [36] & \\
\hline Warm color temperature & Stone $[28]$ & \\
\hline \multicolumn{3}{|l|}{ Being away } \\
\hline Contrasted environments & Tyrväinen et al. [31] & $\begin{array}{l}\text { What is the effect of differ- } \\
\text { ent contrasted environ- } \\
\text { ments on different user } \\
\text { segments? }\end{array}$ \\
\hline \multicolumn{3}{|l|}{ Extent } \\
\hline Reflections from reality & Kaplan [15]; Erdelyi [7] & $\begin{array}{l}\text { To what extend the envi- } \\
\text { ronment needs to reflect a } \\
\text { real and what is the effect } \\
\text { of fantasy? }\end{array}$ \\
\hline \multicolumn{3}{|l|}{ Compatibility } \\
\hline Nature environments & Tyrväinen et al. [31] & $\begin{array}{l}\text { Are there some other envi- } \\
\text { ronments that might work } \\
\text { similarly for various user } \\
\text { segments? }\end{array}$ \\
\hline
\end{tabular}


When talking about educational settings, many factors can cause disturbance to the recovery experience. For the future research, it would be important to consider the learner's cognitive and emotional processes, as well as the individual variance, when interacting with VR [33]. In the context of restorative environments, this can mean for example individual differences on perceiving the visual data, spatial understanding, motivation and special needs. In order to be able to design well-working restorative environments, co-operation is needed between the designers of VR-environments and the actual users, especially when designing environments for the educational field.

Furthermore, one future research avenue would be studying restorative environments and directed attention fatigue among students who need special support for their learning. More research needs to be conducted with children who possess attention deficit disorders (e.g. Attention Deficit Hyperactivity Disorder (ADHD) or Attention Deficit Disorder (ADD). It would be beneficial to know whether there is a connection between attention deficit disorders and directed attention fatigue, for example do children who possess attention deficit disorders become fatigued faster than peers who has no disorders. Symptoms of ADHD and DAF mirrors each other so closely, that the Attention Deficit Disorders Evaluation scale, which is used to measure ADHD, has also been used to measure DAF [19, 35]. Moreover, previous research has proven that natural environments has improved the concentration of children diagnosed with ADHD and ADD [19, 30]. Simulated, VR-based restorative environments would be very beneficial for children with concentration problems and/or attention deficit disorders, at best.

The results of this study are promising, but certain aspects need to be taken into account when generalizing the results. The major limitation of this study was that there was no comparison group. Therefore, more research is needed in order to investigate whether recovery components in VR learning environments could be successfully utilized in educational contexts. Moreover, future research avenues include comparing the effects of VR-Forest and real, natural forest. In addition, in future studies, physiological measures (e.g. galvanic skin response -sensors and heart rate sensors) could be used to have more data about the recovering effects.

Despite the encouraging results, the small sample size was small. Therefore, more research with a bigger sample size will be needed to validate the results in a more solid way and further, to compare the magnitude of the restoration in VR to other ways of having a break. In addition, from the results of this study, it is not clear whether only simulated, VR-based restorative experience can cause these restorative effects, or can whichever calm environment cause same kind of restorative effect. Furthermore, the proposed design principles need to be validated by the future research as suggested. Nevertheless, the results are unambiguous in terms of that VRbased environments can possess recovery effects and thus work as recovery environments at schools or these kinds of environments can be used in learning applications. 


\section{Acknowledgements}

Authors of this paper would like to thank Arto Korhonen for his help with data colecting, Metsämiesten Säätiö Foundation for funding and Zoan Oy for building the modelled VR-environment.

\section{References}

1. Abbott, L. C., Taff, D., Newman, P., Benfield, J. A., \& Mowen, A. J. The influence of natural sounds on attention restoration. Journal of Park \& Recreation Administration, 34(3). (2016).

2. Berman M. G., Jonides J., Kaplan S. The cognitive benefits of interacting with nature. Psychological Science, 19, 1207-1212. (2008). DOI: 10.1111/j.1467-9280.2008.02225.x

3. Berto, R. Exposure to restorative environments helps restore attentional capacity. Journal of Environmental Psychology, 25(3), 249-259. (2005).

4. Boksem, M., Meijman, T., Lorist, M. Effects of mental fatigue on attention: an ERP study. Cognitive Brain Research 25, 107-116. (2005.)

5. Bostic, T.J., McGartland Rubio, D. \& Hood, M. Social Indicators Research 52, 313. https://doi.org/10.1023/A:1007136110218 (2000).

6. Crawford, J. R., \& Henry, J. D. The Positive and Negative Affect Schedule (PANAS): Construct validity, measurement properties and normative data in a large non-clinical sample. British Journal of Clinical Psychology, 43(3), 245-265. (2004).

7. Erdelyi, M. H. Recovery of unavailable perceptual input. Cognitive Psychology, 1(2), 99113. (1970).

8. Felsten, G. Where to take a study break on the college campus: An attention restoration theory perspective. Journal of Environmental Psychology, 29, 160-167. (2009). DOI: 10.1016/j.jenvp.2008.11.006

9. Hair, J., Anderson, R., Tatham, R., \& Black, W. Multivariate data analysis (4th ed.). New York: Prentice Hall (1995).

10. Hartig, T., Lindblom, K., and Ovefelt, K. The Home and Nearhome Area Offer Restoration Opportunities Differentiated by Gender. Scandinavian Housing and Planning Research, 15(4):283-296. (1998.)

11. Hauru, K., Lehvävirta, S., Korpela, K., \& Kotze, D. J. Closure of view to the urban matrix has positive effects on perceived restorativeness in urban forests in Helsinki, Finland. Landscape and Urban Planning, 107(4), 361-369. (2012). DOI: 10.1016/J.LANDURBPLAN.2012.07.002

12. Jacobson, S. Paying Attention or Fatally Distracted? Concentration, Memory, and MultiTasking in a Multi-Media World, 16 Legal Writing 419, (2010).

13. Kaplan, S. \& Kaplan, R. Environment and Cognition. New York: Praeger. (1982).

14. Kaplan, S. \& Berman, M.G. Directed attention as a common resource for executive functioning and self-regulation. Perspectives on Psychological Science, 5, 43-57. (2010).

15. Kaplan, S. The restorative benefits of nature: Toward an integrative framework. Journal of Environmental Psychology, 15(3), 169-182. (1995).

16. Kaplan, S. Meditation, restoration, and the management of mental fatigue. Environment \& Behaviour, 33, 480-506. (2001a). DOI: 10.1177/00139160121973106

17. Kaplan, R. The nature of the view from home: psychological benefits. Environment \& Behaviour, 33(4), 507-542. (2001b). 
18. Korpela, K., Ylén, M., Tyrväinen, L., \& Silvennoinen, H. Determinants of restorative experiences in everyday favourite places. Health \& Place, 14, 636-652. (2008).

19. Kuo F.E, Taylor A.F. A potential natural treatment for attention-deficit/hyperactivity disorder: evidence from a national study. American Journal of Public Health, 94, 1580-1586. (2004). DOI: 10.2105/AJPH.94.9.1580

20. Makransky, G., Terkildsen, T. S., \& Mayer, R. E. (2017). Adding immersive virtual reality to a science lab simulation causes more presence but less learning. Learning and G. Makransky et al. Learning and Instruction, 61, 23-34 (2019.) DOI: 10.1016/j.learninstruc.2017.12.007

21. Marselle, M. R., Irvine, K. N., Lorenzo-Arribas, A., \& Warber, S. L. Does perceived restorativeness mediate the effects of perceived biodiversity and perceived naturalness on emotional well-being following group walks in nature? Journal of Environmental Psychology, 46, 217-232. (2016).

22. Meyers, D. Psychology. 9th ed., W. H. Freeman \& Co. (2009).

23. Miller, M. What College Teachers Should Know About Memory: A Perspective from Cognitive Psychology, 59 College Teaching, 117-122. (2011).

24. Nordh, H., Hartig, T., Hagerhall, C.M., Fry, G. Components of small urban parks that predict the possibility for restoration. Urban Forestry \& Urban Greening, 8, 225-235. (2009).

25. Ratcliffe, E., Gatersleben, B., \& Sowden, P. T. Bird sounds and their contributions to perceived attention restoration and stress recovery. Journal of Environmental Psychology, 36, 221-228. (2013).

26. Ryan, R. M., \& Frederick, C. M. On energy, personality, and health: Subjective vitality as a dynamic reflection of well-being. Journal of Personality, 65, 529-565. (1997).

27. Staats, H., Kieviet, A., and Hartig T. Where to Recover from Attentional Fatigue: An Expectancy-value Analysis of Environmental Preference. Journal of Environmental Psychology, 23(2):147-157. (2003.)

28. Stone, N. J. Environmental view and color for a simulated telemarketing task. Journal of Environmental Psychology, 23(1), 63-78. (2003).

29. Stigsdotter, U. K., Corazon, S. S., Sidenius, U., Refshauge, A. D., \& Grahn, P. Forest design for mental health promotion-Using perceived sensory dimensions to elicit restorative responses. Landscape and Urban Planning, 160, 1-15. (2017).

30. Taylor F.A, Kuo F.E: Children with attention deficits concentrate better after walk in the park. Journal of Attention Disorders, 12, 402-409. (2009).

31. Tyrväinen, L., Ojala, A., Korpela, K., Lanki, T., Tsunetsugu, Y., \& Kagawa, T. The influence of urban green environments on stress relief measures: A field experiment. Journal of Environmental Psychology, 38, 1-9. (2014).

32. Van den Berg, A., Koole, S. L., \& Van der Wulp, N. Y. Environmental preference and restoration: How are they related? Journal of Environmental Psychology, 23, 135-146. (2003).

33. Vesisenaho, M, Juntunen, M., Häkkinen, P, Pöysä-Tarhonen, J., Miakush, I., Fagerlund, J. $\&$ Parviainen, T. Virtual reality in education: Focus on the role of emotions and physiological reactivity. Journal of Virtual Worlds Research, 12(1), 1-15. (2019).

34. Watson, D., Clark, L. A., \& Tellegen, A. Development and validation of brief measures of positive and negative affect: The PANAS scales. Journal of Personality and Social Psychology, 54, 1063-1070. (1988).

35. Wells, N. M. At home with nature: Effects of "greenness" on children's cognitive function. Environment and Behaviour 32, 775-795. (2000). 
36. White, M., Smith, A., Humphryes, K., Pahl, S., Snelling, D., \& Depledge, M. Blue space: The importance of water for preference, affect, and restorativeness ratings of natural and built scenes. Journal of Environmental Psychology, 30(4), 482-493. (2010).

37. Wickens, C. D., \& McCarley, J. Applied attention theory. BocaRaton, FL: Taylor \& Francis. (2008). 